\title{
PATIENTS' SATISFACTION WITH SEXUAL AND REPRODUCTIVE HEALTH SERVICES DELIVERED IN HIV CLINICS ACROSS EUROPEAN REGIONS
}

\author{
Tom Platteau1, Matthias C. Müller², Sibylle Nideröst ${ }^{3}$, Peter Csepe ${ }^{4}$, Nikos Dedes ${ }^{5}$, Ludwig Apers ${ }^{1}$, \\ Ward Schrooten ${ }^{6}$, Christiana Nöstlinger ${ }^{7}$; Eurosupport 5 Study Group \\ 'Department of Clinical Sciences, Institute of Tropical Medicine, Antwerp, Belgium \\ 2Department of Infectious Diseases, Medical Clinic and Policlinic IV, Ludwig Maximilian University, Munich, Germany \\ ${ }^{3}$ University of Applied Sciences Northwestern Switzerland, School of Social Work, Institute for Integration and Participation, Olten, Switzerland \\ ${ }^{4}$ Department of Public Health, Semmelweis University, Budapest, Hungary \\ ${ }^{5}$ European AIDS Treatment Group, Athens, Greece \\ ${ }^{6}$ University of Hasselt, Hasselt, Belgium \\ ${ }^{7}$ Department of Public Health and IHAC (ITM's HIV/AIDS Center), Institute of Tropical Medicine, Antwerp, Belgium
}

\begin{abstract}
SUMMARY
Background: Throughout Europe, differences in satisfaction with HIV-care of people living with HIV (PLHIV) persist, despite a tendency towards harmonisation of policy and management.

Methods: A European sample of 1,549 PLHIV responded to an anonymous questionnaire assessing demographic background, general health, mental health, sexual health, and HIV-service provision. We compared the results across 3 regions: Western, Southern and Central/Eastern Europe.

Results: PLHIV differed in several socio-demographic variables (gender, migrant status, sexual orientation, and financial situation) as well as specific psychosocial aspects (HIV-related discrimination, satisfaction with sexual and reproductive health (SRH) services in HIV-care settings, and complaints about service provision). Using multivariate analysis, a predictive model for satisfaction with SRH services in HIV clinics was developed, resulting into region of residence, and participants' satisfaction with their own health status as significant predictors.

Conclusions: Better integration of SRH services in HIV-care should be encouraged. Service providers should be trained and encouraged to discuss SRH issues with their patients to create a supportive environment, free of discrimination. More time should be allocated to discuss SRH issues with individual patients.
\end{abstract}

Key words: sexual and reproductive health, HIV-care, Europe

Address for correspondence: T. Platteau, Department of Clinical Sciences, Nationalestraat 155, 2000 Antwerp, Belgium. E-mail: tplatteau@itg.be

\section{INTRODUCTION}

HIV continues to be a public health problem in Europe. In the European Economic Area (EEA) - European Union Member States, Norway, Iceland, and Liechtenstein - and Switzerland, 28,038 new HIV cases were reported in 2011, a rate of 5.7 per 100,000 population (1). The four countries with the highest rates were Estonia, Latvia, Belgium, and the United Kingdom, with rates above 10 per 100,000 population. The predominant mode of transmission of HIV in the EU/EEA-region and Switzerland is sex between men, accounting for 39\% (10,855 cases) of the HIVdiagnoses reported in 2011, followed by heterosexual transmission excluding individuals originating from countries with generalised epidemics (23\%). For $19 \%$ of the newly diagnosed cases in 2011 , the transmission mode was unknown (1). While trends towards stronger harmonisation of HIV policy and management across Europe have been observed, there are indications that evidencebased policies, programmes and services are still implemented differently in European countries (2). This may have an impact on patients' satisfaction with health care services. A recent review gathered evidence on perceived service quality of HIV-services. Several factors were found to improve patient's satisfaction. They were either related to individual health care provider (i.e. knowledge, caring and respectful attitude, communication skills, and information provision) or to organisations (responsive and flexible services) (3).

In this article we present a subset analysis using data from a European public health project on sexual and reproductive health needs of people living with HIV (PLHIV) in 14 European countries. Details on the study design and overall results are described elsewhere (4). Here we compare socio-demographic variables, measures of satisfaction with sexual and reproductive health services delivered in HIV clinics, and perceived levels of HIV-related discrimination across three European regions. The identified critical differences in HIV-service provision could inform HIV policy makers and service providers to improve care. 


\section{MATERIALS AND METHODS}

\section{Procedures}

The research was carried out in a network of 17 HIV treatment and research centres in 14 European countries between March and October 2007. A self-administered, anonymous questionnaire was developed including questions on demographic background characteristics, general health related aspects, mental health, sexual health, and HIV-service provision. It was translated into 12 languages, and was distributed to consecutive patients at the collaborating sites. Anonymously filled-in questionnaires were returned to the coordinating centre, using a prepaid envelope. Inclusion criteria were: giving informed consent for voluntary participation, being able to read and understand the questions, and being diagnosed HIV-positive at least 6 months prior to the assessment. Ethical approval was obtained at the coordinating site (the Institute of Tropical Medicine, University of Antwerp).

\section{Measures}

Education level was divided into high (at least 12 years of education), and low (less than 12 years of education) categories. Scores on satisfaction with health and SRH service delivery were scored on a visual analogue-score from 0/10 ('not at all satisfied') - 10/10 ('completely satisfied'). Discrimination was assessed as 'feeling discriminated in relation to your HIV infection during the last three years'.

\section{Statistical Analysis}

Statistical analysis was performed using SPSS 20. Descriptive and univariate analyses were carried out. Chi-Square tests were used for categorical variables, one-way ANOVA for continuous variables. Using linear regression, a predictive model for satisfaction with SRH-services in European HIV clinics was developed. Selected variables were entered into the multivariate analysis. The linear regression was carried out using a forward step model on the basis of likelihood ratio, with a cut-off of 0.500 ( $\mathrm{p}$-in value is 0.05 , p-out is 0.10 ). In order to compare different European regions, countries were divided into three groups: Western Europe (WE: Austria, Belgium, Germany, Switzerland, the United Kingdom), Southern Europe (SE: Greece, Italy, Portugal, Spain), and Central/Eastern Europe (C/EE: the Czech Republic, Hungary, Latvia, Poland, the Slovak Republic). In order to assess the impact of 'region', 2 dummy variables were created for the regions, with Western Europe as reference. A significance level of 5\% was applied. Percentages for each question were calculated on the number of valid questionnaires for that question.

\section{RESULTS}

A total of 1,549 questionnaires were returned $(75 \%$ men, $25 \%$ women). Overall response rate was $42 \%$, with variances between WE (45.8\%), SE (32.7\%), and C/EE (37.2\%). Returned questionnaires were disproportionally distributed over regional clusters: WE (63\%, seven participating centres), SE (20\%; five participating centres), $\mathrm{C} / \mathrm{EE}$ (17\%; five participating centres).

\section{Descriptive Statistics}

Participants from WE were older (mean age 44.3 years; 95\% CI 43.6-44.9), men (79.1\%) and came more often from a migrant background (26.2\%) compared to SE (40.1 years; $95 \%$ CI 38.9-41.3), men (72.8\%), migrant (22.7\%), and C/EE (37.6 years; 95\% CI 36.2-38.9), men (60.5\%), migrant (7.5\%). For these differences (age, gender, proportion of migrants) p-value was always $<0.001$. Satisfaction with general health also differed significantly $(\mathrm{p}=0.001)$ between respondents from WE (mean 7.19/10; 95\% CI 7.05-7.34), SE (mean 7.31/10; 95\% CI 7.04-7.59) and C/EE (mean 6.64/10; 95\% CI 6.35-6.94). Satisfaction with SRH service delivery differed between the regions, with lowest levels of satisfaction in $\mathrm{C} / \mathrm{EE}$. In addition, patients from $\mathrm{C} / \mathrm{EE}$ experienced significant higher levels of discrimination relating to HIV, however, not specifically by health care providers (WE 15.4\%; SE 17.2\%; C/EE 21\%; p=0.113). An overview of socio-demographic variables and differences in satisfaction with SRH-services delivered in HIV clinics is provided in Table 1.

\section{Multivariate Analysis}

In multivariate analysis, satisfaction with SRH-services was significantly correlated with patients' satisfaction with their general health, and the region they stemmed from (Table 2).

\section{DISCUSSION}

In this article, we compared socio-demographic variables from people living with HIV in Western, Southern, and Central/Eastern Europe as well as satisfaction with SRH-services delivered in HIV clinics, and perceived levels of HIV-related discrimination across the three defined European regions.

\section{Socio-demographic Differences between Participants from the Regions}

Participants from the three defined regions differed significantly on several socio-demographic aspects, such as age, gender, sexual orientation, migration background, and financial problems. Some aspects (for instance sexual orientation and migration background) reflect the epidemiological variance throughout Europe, affecting more MSM in Western Europe and less people living with a migrant background in C/EE. Employment status did not differ between the regions, whereas financial problems were more prevalent in $\mathrm{C} / \mathrm{EE}$ (and to a lesser extent in $\mathrm{SE}$ ).

\section{Differences in Satisfaction with SRH-services between the Regions}

The univariate analysis showed several significant differences between the regions in degrees of satisfaction with SRH-services in HIV clinics. Factors on the interpersonal level (relationship health care professional-patient) as well as on the organisational level have been shown to influence patients' satisfaction with services (3). In our study, differences on both levels were found. A lack of time reflects difficulties on the organisational level, while perceived quality of the relationship with the service provider and a lack of openness to discuss SRH address the relationship be- 
Table 1. Overview of socio-demographic variables

\begin{tabular}{|c|c|c|c|c|c|}
\hline Variable & $\begin{array}{l}\text { Western Europe } \\
\qquad \mathrm{N}(\%)\end{array}$ & $\begin{array}{l}\text { Southern Europe } \\
\qquad \mathrm{N}(\%)\end{array}$ & $\begin{array}{l}\text { Central/Eastern } \\
\text { Europe N (\%) }\end{array}$ & $\begin{array}{l}\text { Total sample } \mathrm{N} \\
(\%)\end{array}$ & $\mathrm{p}$-value \\
\hline \multicolumn{5}{|l|}{ Gender $(n=1,545)$} & $<0.001$ \\
\hline Male & $773(79.1)$ & $220(72.8)$ & $161(60.5)$ & $1,154(74.7)$ & \\
\hline Female & $204(20.9)$ & $82(27.2)$ & $105(39.5)$ & $39(25.3)$ & \\
\hline \multicolumn{5}{|l|}{ Sexual orientation $(n=1,491)$} & $<0.001$ \\
\hline Heterosexual & $339(35.9)$ & $145(51.6)$ & $131(49.2)$ & $615(41.2)$ & \\
\hline Homo/bisexual & 605 (64.1) & $136(48.4)$ & $135(50.8)$ & $876(58.8)$ & \\
\hline \multicolumn{5}{|l|}{ Country of origin $(n=1,539)$} & $<0.001$ \\
\hline Country of distribution & $714(73.8)$ & $235(77.3)$ & $247(92.5)$ & $1,196(77.7)$ & \\
\hline Migrant & $254(26.2)$ & $69(22.7)$ & $20(7.5)$ & $343(22.3)$ & \\
\hline \multicolumn{5}{|l|}{ Education $(n=1,473)$} & 0.100 \\
\hline High (at least 12 years education) & $750(81.6)$ & $224(76.5)$ & $216(82.8)$ & $1,190(80.8)$ & \\
\hline Low (less than 12 years education & $169(18.4)$ & $69(23.5)$ & $45(17.2)$ & $283(19.2)$ & \\
\hline \multicolumn{5}{|l|}{ Financial problems $(n=1,502)$} & $<0.001$ \\
\hline Financial problems & $288(30.6)$ & $122(40.7)$ & $135(51.9)$ & $545(36.3)$ & \\
\hline No financial problems & $654(69.4)$ & $178(59.3)$ & $125(48.1)$ & $957(63.7)$ & \\
\hline \multicolumn{5}{|l|}{ Employment status $(\mathrm{n}=1,545)$} & 0.857 \\
\hline Employed & $589(60.5)$ & $189(62.2)$ & $164(61.4)$ & $942(61.0)$ & \\
\hline Unemployed & $385(39.5)$ & $115(37.8)$ & $103(38.6)$ & $603(39.0)$ & \\
\hline \multicolumn{5}{|l|}{ Experiences of discrimination } & 0.005 \\
\hline Yes & $278(29.4)$ & $89(31.1)$ & $101(40.1)$ & $468(31.6)$ & \\
\hline No & $666(70.6)$ & $197(68.9)$ & $151(59.9)$ & $1,014(68.4)$ & \\
\hline \multicolumn{5}{|l|}{ Satisfaction with service delivery $(n=1,407)$} & $<0.001$ \\
\hline \multirow{2}{*}{$\begin{array}{l}\text { Satisfaction with sexual and reproductive } \\
\text { health-services delivered in HIV-clinics }{ }^{\text {a }}\end{array}$} & 7.11 & 6.28 & 6.00 & 6.76 & \\
\hline & $(6.93-7.28)$ & $(5.92-6.64)$ & $(5.64-6.37)$ & $(6.61-6.90)$ & \\
\hline \multicolumn{6}{|l|}{ Complaints of service delivery } \\
\hline Not enough time & $107(11.3)$ & $69(22.8)$ & $90(33.7)$ & $266(17.5)$ & $<0.001$ \\
\hline $\begin{array}{l}\text { Not enough openness to discuss sexual } \\
\text { and reproductive health }\end{array}$ & $73(7.7)$ & $45(14.9)$ & $60(22.5)$ & $178(11.7)$ & $<0.001$ \\
\hline $\begin{array}{l}\text { I don't have a good relation with a health } \\
\text { care provider }\end{array}$ & $42(4.4)$ & $9(3.0)$ & $23(8.6)$ & $74(4.9)$ & 0.005 \\
\hline
\end{tabular}

a Visual analogue-score: Mean score on the scale ranging from 0/10 ('not at all satisfied') - 10/10 ('completely satisfied'), and 95\% confidence interval

tween PLHIV and their service provider. Considering the latter, it has been shown that discussing SRH and prevention-related topics with patients is a contribution to HIV prevention (5). Interventions that offer family planning and/or sexual health services for PLHIV result mostly in positive outcomes, such as increased condom and contraceptive use, or a decrease in unplanned pregnancies

Table 2. Patient's satisfaction with sexual and reproductive health services: multiple linear regression model

\begin{tabular}{|l|c|c|c|}
\hline & Coefficient & \multicolumn{2}{|c|}{$95 \%$ Confidence Interval } \\
\hline Constant & 6.290 & 5.762 & 6.82 \\
\hline Central/Eastern Europe $^{\text {a }}$ & -1.108 & -1.522 & -0.695 \\
\hline Southern Europe $^{\text {a }}$ & -0.883 & -1.294 & -0.473 \\
\hline State of health & 0.117 & 0.049 & 0.185 \\
\hline
\end{tabular}

a Compared to the Western Europe, with reference value ' 1 ' and sexually transmitted infections (STI) (5). Service providers who lack the skills to discuss such sensitive issues with their HIV-positive patients should therefore be offered training on how to integrate SRH into HIV care.

\section{HIV-related Discrimination}

Experiences of HIV-discrimination differed between the regions in the univariate analysis, i.e. one out of three patients in $\mathrm{WE}$ and $\mathrm{SE}$ reported having been discriminated, compared to $40 \%$ in C/EE. Given the high proportion of MSM in the sample, these numbers may also reflect high levels of 'homophobia' in (certain) C/EE countries $(6,7)$. However, this hypothesis needs to be explored more in depth with further research.

Other studies have also found comparable proportions of PL HIV experiencing discrimination because of their HIV-status, e.g. $27 \%$ in France (8). A study of Sprague et al. showed that $40 \%$ of 
PLHIV anticipated HIV-related stigma, which constituted a barrier to accessing testing and care (9). Previous research on knowledge about HIV-transmission risk among health care professionals in Serbia showed that the knowledge of health care professionals was deficient, which led to discriminatory attitudes towards HIVpositive patients (10). Research in Albania among people living with HIV revealed barriers to care on both societal and health care level: social stigma, unmet social needs, and a lack of knowledge on HIV among health care professionals (11). Thus, HIV-related discrimination seems to persist in Europe.

\section{Multivariate Analysis on Satisfaction with SRH- services}

Using multivariate analysis, a model was developed to predict patients' satisfaction with sexual and reproductive health services. A model with only 2 variables was found to predict patients' satisfaction: their satisfaction with their (general) health status, and the region where they live, regardless gender, sexual orientation, and other socio-demographic variables. Region was also found to be strongly associated, and even predictive, for the satisfaction with the SRH-services in HIV clinics. Differences in satisfaction with health facilities and psychosocial variables between European regions are in line with the results published in the ECDC report, documenting differences in the access to HIV treatment, prevention, and care for migrants in different European countries (12).

\section{Limitations of the Study}

We acknowledge that the study has some methodological limitations. We used a self-selected convenience sample in 14 European countries, which we grouped into three regions. The situation of PLHIV (discrimination, etc.) and health care organisation (cost for care and treatment, centralisation vs. decentralisation of care, etc.) may differ between countries within one region, which were not taken into account in the analysis. For instance, in Estonia, differences were found even between cities and regions (13). Participants appeared to be unequally distributed across the European regions, thus only partially reflecting epidemiological patterns. Therefore, our findings cannot be generalised to the overall population of PLHIV in Europe. The response rate was $42 \%$ (32.7-45.8\%). Taken into account that participants were asked to fill in the questionnaire at home, the length of the questionnaire (18-20 pages, depending on the language), the sensitive nature of the topic, and absence of any incentive, the response rate was considered acceptable.

Because our sample was clinic-based, only people who had access to service provision filled in the questionnaire. The findings of this study could therefore be biased, and asking PLHIV with difficult or no access to care could yield a different picture, for instance with respect to perceived discrimination. Data stem from six years ago, and the situation may have changed since then. However, during a more recent European conference in Copenhagen (HIV in Europe; March 19-20, 2012), robust evidence was presented on an existing gap between Eastern and Western Europe in relation to HIV prevention, and access to treatment and care. Eastern European countries have much more difficulties to guarantee the quality of HIV care, i.e. a stigma- and discrimination-free environment, and state-of-the-art access to HIV care and treatment. Eastern Europe and Central Asia are the major regions accounting for the increase of new HIV cases in Europe (14) and the estimated coverage of treatment for PLHIV in this region (23\%) is among the worst worldwide (15). Contextual variables, such as (national) health policies and societal attitudes, might be important factors influencing patient's satisfaction with services, but such variables were not assessed in this study due to its original focus on SRH needs and sexual risk reduction.

\section{CONCLUSIONS}

In spite of the above mentioned study limitations, our large sample size and country representation give a relevant snapshot on how HIV-positive patients perceive SRH-services in HIV treatment centres. Our data show the need for a tailored and culture-sensitive approach across Europe; societal acceptance, better integration of SRH and HIV prevention services could improve satisfaction with SRH service delivery for PLHIV. Improved services could subsequently lead to a reduction of the ongoing transmission of HIV in Europe (7). Our findings also highlight the need for a supportive environment, free of discrimination, allowing for an open discussion of SRH between service providers and PLHIV, using different tools encouraging safer sex behaviour in an overall context of SRH and rights (5). For the future research, an in-depth evaluation of the integration of SRH-issues in HIV care in the context of general health care systems and policy contexts in a comparative cross-European perspective would contribute to better understanding of the existing differences found in this study.

\section{Acknowledgements}

We are grateful to all study participants for contributing to this study and to the investigators at the participating centres: Austria: Birgit Mumelter (University of Innsbruck), Gabriele Schmied (European Centre, Vienna); Belgium: Ruth Borms (Sensoa, Antwerp); Czech Republic: Ivo Prochazka (University of Prague); Germany: Johannes Bogner (Ludwig Maximilians University, Munich), Werner Becker and Ramona Volkert (Private Practice, Munich), Andrea Niedermeier (University Clinic for Dermatology, Munich), Martin Karwat (Private Practice, Munich); Greece: Nikos Dedes (Synthesis, Athens); Hungary: Peter Csepe (Semmelweis University, Budapest); Italy: Gloriana Bartoli and Carlo Giaquinto (University of Padua, Padua); Caterina Uberti-Foppa and Giulia Galotta (HSR Ospedale, Milan); Latvia: Anda Vaisla (Latvian Family Planning Association, Riga); Poland: Michal Pozdal and Zbigniew Izdebski (University of Zielona Gora ); Portugal: Luis Caldeira (Hospital Santa Maria, Lisbon) and Sonia Ferreira Dias (Institute of Hygiene and Tropical Medicine, Lisbon) for contributions to the manuscript; Spain: Victoria Gordillo (University Complutense of Madrid); UK: Ed Wilkins and Cinthia Murphy (Pennine Acute Hospitals NHS Trust, Manchester).

\section{Funding}

EUROSUPPORT V received funding from the European Commission, SANCO/Public Health, grant agreement nr. 2004314. EUROSUPPORT $\mathrm{V}$ thanks the Swiss National Science Foundation and the Swiss HIV Cohort Study for funding, support and co-operation. 


\section{REFERENCES}

1. European Centre for Disease Prevention and Control; WHO Regional Office for Europe. HIV/AIDS surveillance in Europe 2011. Stockholm: ECDC; 2012.

2. European Centre for Disease Prevention and Control. Implementing the Dublin Declaration on Partnership to Fight HIV/AIDS in Europe and Central Asia: 2010 progress report. Stockholm: ECDC; 2010.

3. Land L, Nixon S, Ross JD. Patient-derived outcome measures for HIV services in the developed world: a systematic review. Int J STD AIDS. 2011 Aug;22(8):430-5.

4. Nöstlinger C, Nideröst S, Platteau T, Müller MC, Staneková D, Gredig D, et al.; Swiss HIV Cohort Study and The Eurosupport Study Group. Sexual protection behavior in HIV-positive gay men: testing a modified information-motivation-behavioral skills model. Arch Sex Behav. 2011 Aug;40(4):817-27.

5. Brickley DB, Almers L, Kennedy CE, Spaulding AB, Mirjahangir J, Kennedy GE, et al. Sexual and reproductive health services for people living with HIV: a systematic review. AIDS Care. 2011 Mar;23(3):303-14.

6. Stulhofer A, Rimac I. Determinants of homonegativity in Europe. J Sex Res. 2009 Jan-Feb;46(1):24-32.

7. Rechel B. HIV/AIDS in the countries of the former Soviet Union: societal and attitudinal challenges. Cent Eur J Public Health. 2010 Jun;18(2):1105.

8. Peretti-Watel P, Spire B, Obadia Y, Moatti JP; VESPA Group. Discrimination against HIV-infected people and the spread of HIV: some evidence from France. PLoS One. 2007 May 2;2(5):e411.
9. Sprague L, Voinova J, Ankiersztejn-Bartczak M, Chilcevschii I, Karatas S, Polyantsev P. HIV-related stigma: late testing, late treatment. A crossanalysis of findings from the people living with HIV stigma index in Estonia, Moldova, Poland, Turkey, and Ukraine. 2011.

10. Kocić B, Petrović B, Bogdanović D, Jovanović J, Nikić D, Nikolić M. Professional risk, knowledge, attitudes and practice of health care personnel in Serbia with regard to HIV and AIDS. Cent Eur J Public Health. 2008 Sep;16(3):134-7.

11. Morrison SD, Banushi VH, Sarnquist C, Gashi VH, Osterberg L, Maldonado Y, et al. Barriers to care and current medical and social needs of HIV-positive patients in Albania. Cent Eur J Public Health. 2011 Jun;19(2):91-7.

12. European Centre for Disease Prevention and Control. Migrant health access to HIV prevention, treatment and care for migrant populations in EU/EEA countries. Stockholm: ECDC; 2009.

13. Rüütel K, Uusküla A, Minossenko A, Loit HM. Quality of life of people living with HIV and AIDS in Estonia. Cent Eur J Public Health. 2008 Sep;16(3):111-5.

14. Joint United Nations Programme on HIV/AIDS. World AIDS Day report 2011. Geneva: UNAIDS; 2011.

15. World Health Organization; Joint United Nations Programme on HIV/ AIDS; United Nations Children's Fund. Global HIV/AIDS response: epidemic update and health sector progress towards universal access: progress report 2011. Geneva: WHO; 2011

Received September 13, 2012 Accepted in revised form May 13, 2013 